\title{
Mild exercise training, cardioprotection and stress genes profile
}

\author{
Marina Marini • Rosa Lapalombella • Vittoria Margonato • \\ Raffaella Ronchi • Michele Samaja • Cristina Scapin - Luisa Gorza • \\ Tullia Maraldi • Paolo Carinci · Carlo Ventura • Arsenio Veicsteinas
}

Accepted: 27 November 2006 / Published online: 6 January 2007

(C) Springer-Verlag 2006

\begin{abstract}
To improve current knowledge of the molecular mechanisms underlying exercise-induced cardioprotection in a rat model of mild exercise training, Sprague-Dawley rats were trained to run on a
\end{abstract}

Electronic supplementary material The online version of this article (doi:10.1007/s00421-006-0369-4) contains supplementary material, which is available to authorized users.

M. Marini $(\bowtie) \cdot$ R. Lapalombella $\cdot$ P. Carinci

Department of Histology, Embryology,

and Applied Biology, University of Bologna,

Via Belmeloro, 8, 40126 Bologna, Italy

e-mail:marina.marini@unibo.it

\section{Margonato $\cdot$ A. Veicsteinas}

Institute of Physical Exercise, Health and Sport Activities,

University of Milan, Milan, Italy

R. Ronchi $\cdot$ M. Samaja

Department of Medicine, Surgery and Dentistry,

University of Milan, Milan, Italy

C. Scapin · L. Gorza

Department of Biomedical Sciences,

University of Padova, Padova, Italy

T. Maraldi

Department of Biochemistry "G. Moruzzi",

University of Bologna, Bologna, Italy

C. Ventura

Institute of Cardiology, University of Bologna, Bologna, Italy

A. Veicsteinas

Center of Sport Medicine,

Don Gnocchi Foundation, Milan, Italy

M. Marini

Istituto Interuniversitario di Miologia, Chieti, Italy treadmill up to $55 \%$ of their maximal oxygen uptake for $1 \mathrm{~h} /$ day, 3 days/week, 14 weeks, with age-matched sedentary controls ( $n=20$ /group). Rats were sacrificed $48 \mathrm{~h}$ after the last training session. Despite lack of cardiac hypertrophy, training decreased blood hemoglobin $(7.94 \pm 0.21 \mathrm{mM}$ vs. $8.78 \pm 0.23 \mathrm{mM}$, mean $\pm \mathrm{SE}$, $P=0.01)$ and increased both plasma malondialdehyde $(0.139 \pm 0.005 \mathrm{mM}$ vs. $0.085 \pm 0.009 \mathrm{mM}, P=0.05)$ and the activity of Mn-superoxide dismutase $(11.6 \pm 0.6$ vs. $16.5 \pm 1.6 \mathrm{mU} / \mu \mathrm{g}, P=0.01)$, whereas total superoxide dismutase activity was unaffected. When subjected to 30-min ischemia followed by 90 min reperfusion, hearts from trained rats $(n=5)$ displayed reduced infarct size as compared to controls $(37.26 \pm 0.92 \%$ vs. $49.09 \pm 2.11 \%$ of risk area, $P=0.04)$. The biochemical analyses in the myocardium, which included gene expression profiles, realtime PCR, Western blot and determination of enzymatic activity, showed training-induced upregulation of the following mRNAs and/or proteins: growtharrest and DNA-damage induced 153 (GADD153/ CHOP), heme-oxygenase-1 (HO-1), cyclooxygenase-2 (Cox-2), heat-shock protein 70/72 (HSP70/72), whereas heat-shock protein 60 (HSP60) and glucoseregulated protein 75 (GRP75) were decreased. As a whole, these data indicate that mild exercise training activates a second window of myocardial protection against ischemia/reperfusion by upregulating a number of protective genes, thereby warranting further investigation in man.

Keywords Gene expression - Rat heart .

Oxidative stress $\cdot \mathrm{Hsp} 70 / 72$.

Ischemia-reperfusion 


\section{Introduction}

The cardioprotective effects of exercise training are well known and out of any dispute. Recent studies have clearly shown that training at $>60 \% \quad V \mathrm{O}_{2 \max }$ increases myocardial tolerance to ischemia-reperfusion (I-R) (Strøm et al. 2005), improves cardiac performance and ameliorates the cell defence capacity against stress (Powers et al. 2002; Freimann et al. 2005). Most probably, the mechanisms underlying training-induced cardioprotection resemble those elicited by ischemic preconditioning (IP), e.g., the phenomenon whereby short ischemic episodes given before a major ischemic insult lead to into endogenous cardioprotection (Yellon and Downey 2003). Training may induce IP by emulating minor local ischemic episodes, where ischemia is intended as short periods of time during which the supply of blood and oxygen to tissues is limited with respect to the tissue needs (Hearse 1994). It is acknowledged that cardioprotection can be exerted in two temporal windows, of which the first is active in the minutes-hours period after the conditioning stress, whereas the second, the so-called "second window of protection" (SWOP), is active 13 days later (Bolli 2000). As exercise training is generally intended to have long-lasting effects, it is likely that training-induced cardioprotection is more specific for the SWOP than for the first window of protection.

In the perspective of emphasizing the potentially protective effect of training by enlarging the number of the subjects that may benefit, it is critical to assess whether mild training intensity is still capable to induce IP as high training intensity does. Other studies have addressed this issue in the past. Bronikowski et al. (2003) reported a quantitative gene expression analysis in mice exposed to active life style over 16 generations. Schweizer et al. (2005) measured the changes in gene expression in rats exercising each-other-day with a running wheel. Other studies showed that low-intensity (55-60\% of $\left.V \mathrm{O}_{2 \max }\right)$ exercise training may not allow a sufficient cardioprotection (Starnes et al. 2005). Thus, the purpose of this study is to focus into the effects of a mild training protocol, frequently applied in sedentary middle-age humans, whereby cardiac hypertrophy is prevented. The use of an animal model to apply this protocol was dictated mainly by the necessity to examine early changes in the expression of genes and proteins in the myocardial tissue in addition to phenotypical alterations such as the establishment of cardioprotection. Indeed, early molecular changes may precede the onset of overt cardioprotection, thereby providing an effective way to determine the occurrence of protective effects. To this aim, we trained rats fol- lowing a mild protocol (55\% of $\left.V \mathrm{O}_{2 \max }\right)$ and determined both the parameters of cardioprotection and those relative to the alteration of gene and protein expression. We will show that mild training is capable to exert cardioprotection both at phenotypical and gene/protein levels, thereby supporting to the idea that even mild training may be useful in certain categories of human subjects.

\section{Materials and methods}

\section{Glossary}

The following abbreviations have been used: COX-2, cyclooxygenase-2; Dnaja1, DnaJ-homolog a1 protein; GADD153, Growth arrest and DNA-damage-inducible protein 153; GRP75, glucose-regulated protein 75; HO-1, heme-oxygenase-1; HPLC, high-performance liquid chromatography; HSP60 or HSP70/72, heat shock protein 60 or $70 / 72 ; \mathrm{IkBa}$, inhibitor of nuclear factor $\kappa \mathrm{Ba}$; IP, ischemic preconditioning; I-R, ischemia-reperfusion; MDA, malondialdehyde; PBS, phosphate-buffered saline; PCR, polymerase chain reaction; Por, NADPH-cytochrome p450 oxidoreductase;RPL13a, ribosomal protein L13a; Scya21b, small cytokin a21b; SOD, superoxide dismutase; SWOP, second window of protection; $V \mathrm{O}_{2 \max }$, maximal oxygen uptake; WB, western blot.

\section{Animals and training}

Forty male albino Sprague-Dawley rats (2 months age) were placed in individual cages and fed standard diet without limitations; room temperature was kept at $21 \pm 2^{\circ} \mathrm{C} ; 12 \mathrm{~h}$ of light were automatically alternated to $12 \mathrm{~h}$ of dark. After 1 week of acclimatization, 20 animals were randomly chosen to run on a four lanes treadmill at increasing speed and time of exercise (Fig. 1). At the end of the program, the rats exercised for $1 \mathrm{~h}$ a day, three times a week at $0 \%$ grade, which corresponds to $55 \%$ of $V \mathrm{O}_{2 \max }$ (Wisloff et al. 2001). Control animals were placed on a non-moving treadmill during the training sessions. Animal handling, training protocol and mode of sacrifice were approved by the Ethical Committee on the Use of Laboratory Animals of the Health Authority of Milan (Italy) according to the 86/609/CEE guidelines.

At the end of the program, animals were sacrificed $48 \mathrm{~h}$ after the last training session. In order to avoid diurnal variations in gene expression, all sacrifices were carried out between 10 and 12 a.m. The sacrifice of control rats was alternated with that of trained ones in 


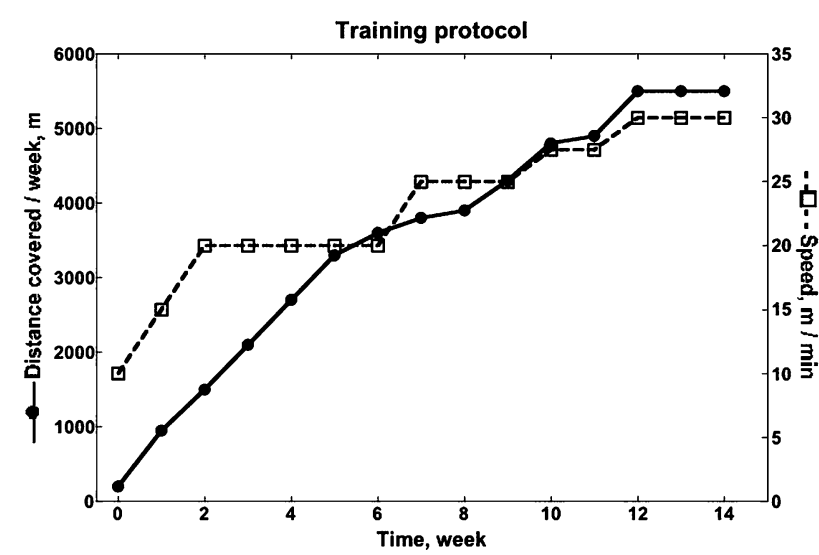

Fig. 1 Training workload (distance travelled per week) and running speed achieved weekly by trained rats

a one-by-one fashion. Rats were assigned randomly to one of the following groups: (1) gene and protein expression; (2) myocardial morphology and blood analysis; and (3) ischemia-reperfusion.

\section{Group $1-$ Gene and protein expression}

Rats were anesthetized $(100 \mathrm{mg} / \mathrm{kg}$ ip heparinized sodium thiopental), then animals were cut open and hearts removed, immediately frozen in liquid nitrogen and stored at $-80^{\circ} \mathrm{C}$ for biochemical analyses. These included the assay of Mn-SOD activity determined by the WST-1 method (Zhou and Prognon 2006) and the TUNEL assay. For this assay, left ventricle cryosections ( $4 \mu \mathrm{m}$ thickness) were stained by Terminal dUTP Nick-End Labelling (TUNEL assay) to detect apoptotic cells. The sections were fixed $45 \mathrm{~min}$ at $4^{\circ} \mathrm{C}$ in $4 \%$ paraformaldehyde, washed in PBS and stained by the APO-BrdU TUNEL assay kit (Invitrogen s.r.l, Milan, Italy) as indicated.

For RNA preparation and quality control, frozen tissue from left ventricles was reduced to powder by means of a sterilized ceramic mortar and pestle. RNA isolation was obtained by TRIZOL ${ }^{\mathrm{TM}}$ (Invitrogen s.r.l., Milan, Italy) (Chomczynski and Sacchi 1987). The presence of RNA degradation was assessed by evaluation of $28 \mathrm{~S}$ and $18 \mathrm{~S}$ band sharpness after denaturing electrophoresis. Since no degradation was found, all preparations were used for the further steps. The absence of contaminating genomic DNA was confirmed by PCR analysis with tubulin promoter-specific primers.

For the analysis of the array, to control for interindividual variation, an equivalent mass of total RNA from each subject in the group was pooled to generate the total RNA sample for probe generation. Reverse transcription was performed making use of Omniscript
Reverse Transcription Kit (Qiagen GmbH, Hilden, Germany). The Stress and Toxicity-focused Arrays (GEArray Q Series ${ }^{\mathrm{TM}}$, SuperArray) were employed. Data were then normalized with respect to the housekeeping gene RPL13a, one of the positive controls in the array.

Real-time PCR was performed in an ABI PRISM 5700 real-time thermal cycler using the SYBR Green kit (Qiagen). The housekeeping gene RPL13a was used for normalization purposes: real-time PCR was initially run with RPL13a primers in order to evaluate the concentration ratio of the pooled cDNAs of the two groups to be compared (control or trained rat hearts), then the concentration of the cDNA pools was adjusted to the same amount of RPL13a cDNA and analyzed with the $2^{-\Delta \Delta C}$ T method (Livak and Schmittgen 2001).

For Semiquantitative Western blot (WB) analysis, cryosections from left ventricle tissue were homogenized in Laemmli electrophoresis sample buffer. Protein concentration was determined using bovine serum albumin as standard, and all procedures were carried out as previously described (Vitadello et al. 2003).

Group 2-Myocardial morphology and blood analysis

Rats were anesthesized and sacrificed as described above. After thoracotomy, a sample of blood was withdrawn by cardiac puncture into a heparinized syringe. Blood was centrifuged and the plasma was stored at $-80^{\circ} \mathrm{C}$ for biochemical evaluations, which included blood hemoglobin concentration (standard cyan-methemoglobin method) and plasma malondialdehyde (MDA) concentration, which was determined by HPLC according to Kawai et al. (1989).

To assess myocardial morphology, hearts were excised, excess water was absorbed on tissue paper, and the heart mass was weighed. Then atria, left and right ventricles were accurately cutoff, trimmed of connective tissue and water, and weighted separately.

\section{Group 3-Ischemia-reperfusion}

Rats were anesthetized by intra-peritoneal injection of sodium pentobarbital $(50 \mathrm{mg} / \mathrm{kg})$. Body temperature was kept constant at $37^{\circ} \mathrm{C}$ by use of a heating platform controlled by a thermostat. Animals were intubated through a tracheotomy and ventilated mechanically (tidal volume $3 \mathrm{ml}$; ventilation rate 50 strokes $/ \mathrm{min}$ ). A left thoracotomy was performed between the $3 \mathrm{rd}$ and 4th rib to allow access to the heart. A silk suture (6/0) was passed around the left coronary artery and a small polyethylene catheter was used to form a snare. All 
rats were allowed $10 \mathrm{~min}$ after completion of the surgical preparation to reach steady state before beginning the protocol. The left coronary artery branch was occluded by pulling the snare and the occluded position was maintained for $30 \mathrm{~min}$ by means of a hemostatic clamp. Hearts were reperfused for $90 \mathrm{~min}$ by releasing the snare, then they were removed, cannulated via the aorta and perfused with $15-20 \mathrm{ml}$ saline at room temperature to wash out the blood. The left coronary branch was re-occluded and a saturated Evans blue solution $(2 \mathrm{ml})$ was injected through the aorta and upstream the occlusion to mark the ischemic zone as the area without the dye. Hearts were then frozen briefly in liquid nitrogen and stored at $-20^{\circ} \mathrm{C}$.

To measure the infarcted area, hearts were cut into five or six transverse slices ( $1 \mathrm{~mm}$ thick). Slices were incubated in triphenyltetrazolium chloride in sodium phosphate buffer at $37^{\circ} \mathrm{C}$ for $20 \mathrm{~min}$ to stain viable cells in the risk zone. Finally, the slices were immersed in $10 \%$ formalin for 4 days to enhance contrast between stained and unstained areas, with the latter representing the infarct size. Stained and unstained areas were calculated from computerized images of the slices using NIH Image software (NIH AutoExtractor 1.51; National Institutes of Health) and averaged for all the slices. The risk area was expressed as a percentage of total ventricle area, i.e., the sum unstained plus redstained area with respect to total ventricle area, whereas the infarct area was expressed as a percentage of the risk area, i.e., unstained area with respect to risk area.

\section{Statistics}

Data are expressed as mean $\pm \mathrm{SE}$. To detect significant differences between the control and the trained group, we performed the two-tailed Student's $t$ test for unpaired observations (GraphPad Prism Software). The significance level was set to $P=0.05$.

Further details of the following methods are supplied in the ESM File 1: evaluation of myocardial SOD activity, array analysis, Real-Time PCR, Western blots analysis, evaluation of blood hemoglobin and plasma MDA concentration.

\section{Results}

Animals, myocardial morphology and blood data

The rats were periodically examined by a veterinary. Their internal organs, examined by a pathologist on the day of sacrifice, appeared to be normal and disease- free. Two control and three trained rats died for causes unrelated to training.

Myocardial morphology, blood and plasma parameters were examined in six control and five trained rats. At the end of the training, rats were leaner than controls (Table 1), but the heart-to-body weight ratio was the same, thereby excluding cardiac hypertrophy. Blood hemoglobin concentration was less, and plasma MDA higher in trained animals than in controls. The activity of Mn-SOD was upregulated in trained rats (Fig. 2), while total SOD activity was the same in the two groups. To assess apoptosis, staining with the Terminal dUTP Nick-End Labeling kit (TUNEL assay) did not detect apoptotic cells neither in control nor trained rats (data not shown).

\section{Ischemia-reperfusion}

The number of rats investigated was four control and five trained. The bottom panel of Fig. 3 shows sample images of infarcted (white), risk (red) and perfused (blue) areas in control and trained rat hearts. Same risk area in the two groups (Fig. 3, left panel) enables to consider the infarcted area as a reliable marker of myocardial susceptibility to I-R. The infarcted area was less in trained animals compared to controls (Fig. 3, right panel, $P=0.04)$.

\section{Gene expression profiles}

The number of rats investigated was eight control and seven trained. For 14 genes (Fig. 4), the level of expression was different in the two groups. The change is uncertain for Dnaja1/Hsj2 and Scya21b, because of their low expression levels. Upregulated genes included those related to apoptosis (Annexin $\mathrm{V}, \mathrm{IkBa} /$ Mad3), proliferation (cyclin D1), growth arrest (GADD153/CHOP, p21 ${ }^{\text {Waf-1 }}$, Mdm2), oxidative stress [Glutathione peroxidase-2 (GPX2), heme-oxygenase-1 (HO-1), cyclooxygenase-2 (COX-2), NADPH-cyto-

Table 1 Heart morphological parameters and blood data. Statistical significance calculated by two-tailed Student $t$ test

\begin{tabular}{lccccc}
\hline Group & Mean & SE & Mean & SE & $P$ \\
& Control, $n=6$ & Trained, $n=5$ & \\
\hline Body weight (g) & 621.0 & 15.0 & 565.0 & 16.0 & 0.031 \\
Heart weight (g) & 3.347 & 0.314 & 3.030 & 0.520 & 0.601 \\
$\begin{array}{l}\text { Heart weight/body } \\
\text { weight } \times 1,000\end{array}$ & 0.110 & 0.003 & 0.119 & 0.006 & 0.133 \\
$\begin{array}{l}\text { Hemoglobin (mM) } \\
\begin{array}{c}\text { Malondialdeyde } \\
(\mathrm{mM})\end{array}\end{array}$ & 0.78 & 0.23 & 7.94 & 0.21 & 0.011 \\
& & 0.009 & 0.139 & 0.005 & 0.001 \\
\hline
\end{tabular}




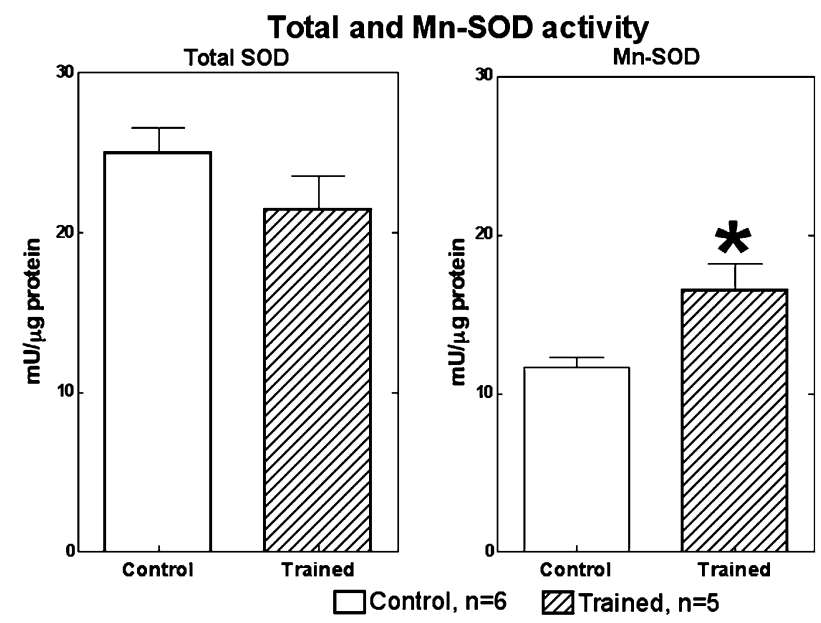

Fig. 2 SOD and Mn-SOD activity $(\mathrm{mU} / \mu \mathrm{g}$ protein $\pm \mathrm{SE})$ in the cardiac tissue of control and trained rats. Difference in Mn-SOD concentration was significant $(P=0.015$ according to two-tailed unpaired $t$ test). Total SOD activity includes $\mathrm{Cu}, \mathrm{Zn}-\mathrm{SOD}$ and Mn-SOD
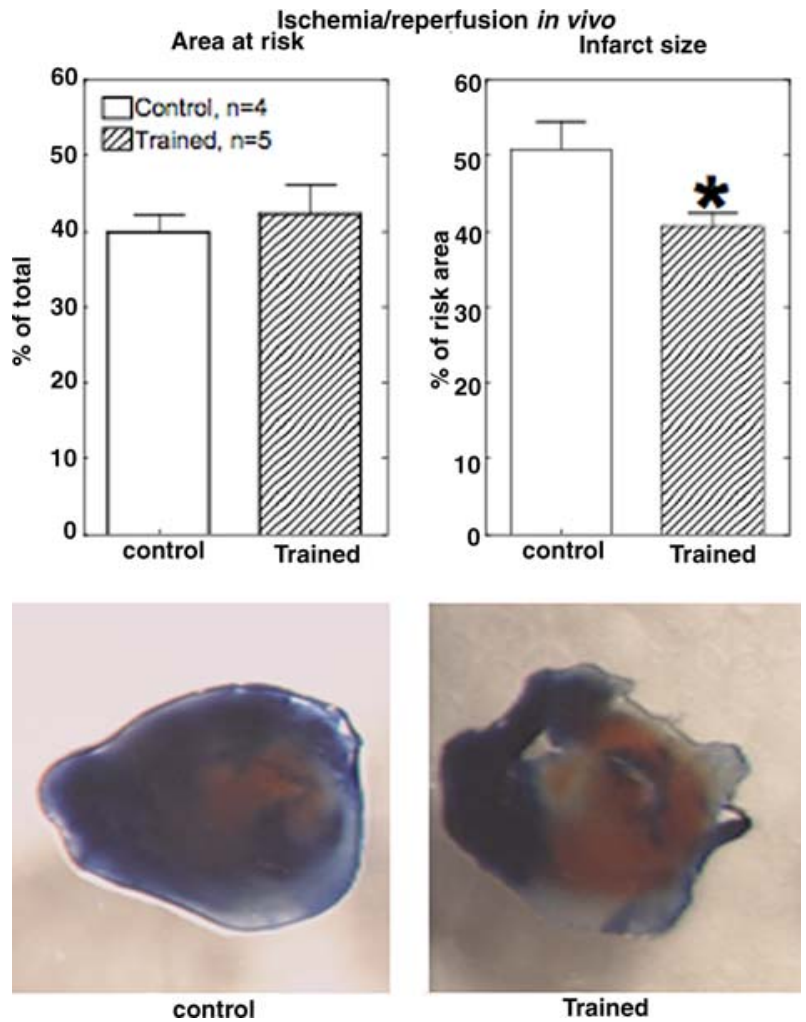

Fig. 3 Top, left panel Area at risk: comparison between hearts of control (4) and trained (5) rats; the area (as percent of total area) was evaluated by injecting Evans Blue, as described in Materials and Methods. Top, right panel Infarcted area: comparison between hearts of control (4) and trained (5) rats; the area is a percent of area at risk and was evaluated as described in Materials and Methods. Bottom Representative sections of myocardia of a control (left) or an exercised (right) rat after coronary ligation, as detailed in the text. Blue, perfused area; white, ischemic area; red + white, area at risk

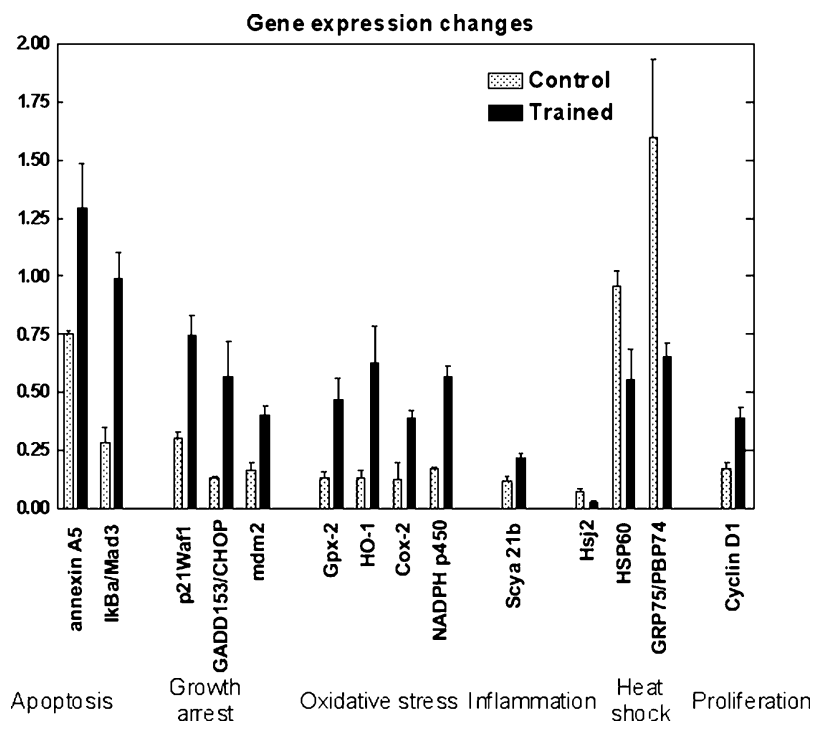

Fig. 4 Genes up- or down-regulated by mild training. Results of three arrays, each corresponding to independent amplification/ hybridization experiments, were averaged. Values are expressed in arbitrary units, after background subtraction and normalization by a housekeeping gene (RPL13a). To each array a pool of equivalent amounts of RNA from hearts of control $(n=8)$ or trained $(n=7)$ rats was hybridized; the array contained 96 genes whose expression change is indicative for stress and toxicity. The expression of the 14 genes here reported significantly differed between the two groups $(P<0.05$ by two-tailed Student's $t$ test $)$

chrome p450 oxidoreductase (Por)] and inflammation (Scya-21a). By contrast, the heating stress pathway genes, i.e., Dnaja1/Hsj2, GRP75/PBP74//Hsp74a/mortalin and Hsp60 were downregulated. No differences were found in the 14 DNA damage and repair genes present in the arrays. The expression level of both $\mathrm{Mn}-$ SOD and Hsp70 mRNAs did not differ among control and trained groups. Full results of the array experiments are reported in ESM File 2, that includes the complete list of the 96 genes. All data were deposited in the National Center for Biotechnology Information (NCBI) Gene Expression Omnibus (GEO) repository and given the Series Record no. GSE3904.

The results of the array were validated by Real-time PCR analysis for GADD153/CHOP, Cox-2, HO-1, Hsp60 and GRP75/PBP74 (Table 2). The upregulation of HO-1 and COX-2 and the downregulation of GRP75/PBP74 and Hsp60 were confirmed.

Table 2 reports also the trained-to-control ratio relative to the expression level of two proteins that were examined by Western blot. The protein level of HO-1 displayed a twofold increase, in agreement with the mRNA expression level, whereas Hsp70 increased $\approx$ tenfold, whilst no difference was found in gene expression. Representative blots are shown in Fig. 5. 
Table 2 Relative (trained versus control ratio) gene expression and protein amount in rat heart expressed as trained versus control ratio

\begin{tabular}{lllll}
\hline Functional group & Gene name (symbol) & Arrays & Real time PCR & Protein (WB) \\
\hline Growth arrest & GADD153/CHOP (Ddit3) & $4.38(0.046)$ & $1.66(0.072)$ & ND \\
Oxidative stress & HO-1 (Hmox1) & $4.88(0.039)$ & $1.79(0.047)$ & $2.06(0.015)$ \\
Oxidative stress & Cox-2 (Ptgs2) & $3.10(0.022)$ & $2.76(0.040)$ & ND \\
Heat shock & Hsp60 & $0.58(0.056)$ & $0.56(0.010)$ & ND \\
Heat shock & GRP75/PBP73/Hsp74a/mortalin & $0.40(0.051)$ & $0.66(0.049)$ & $9.92(<0.001)$ \\
Heat shock & (Hspa9a) & $0.73(\mathrm{NS})$ & $0.63(\mathrm{NS})$ & \\
\hline
\end{tabular}

Gene expression was normalized to the housekeeping gene RPL13a, protein amount, evaluated by Western blot, to a-actinin. Repeated independent evaluations were averaged; statistical significance calculation by two-tailed Student $t$ test gave the $P$ values reported between parenthesis

$N D$ Not done, NS not significant $(P>0.05)$

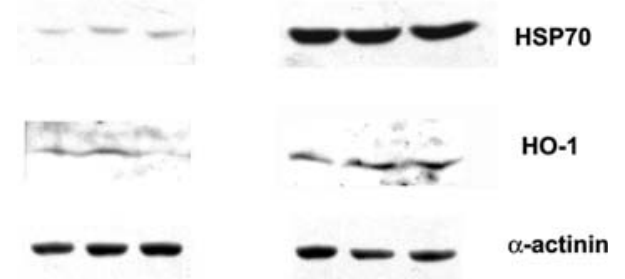

Fig. 5 Representative Western blots of some relevant proteins in control and trained ventricular myocardium. Top to bottom: Hsp70, HO-1; $\alpha$-actinin. Antibody source and dilution used were the following: mouse monoclonal anti-Hsp70 (SPA-810) antibody (Stressgen) 1:50,000; goat polyclonal anti-HO-1 antibody M-19 (SantaCruz) 1:3,000; mouse monoclonal anti-alpha actinin antibody (Sigma) 1:20,000

\section{Discussion}

In this study, we show that mild training, which resembles the procedure advised for middle-aged humans, can protect hearts against I-R similarly to well-documented, more intense $\left(>60 \% V \mathrm{O}_{2 \max }\right)$ training procedures (Powers et al. 2002; Strøm et al. 2005; Freimann et al. 2005). Indeed, the size of the infarcted area with respect to the risk area, which is not affected by training, decreases by $12 \%$ following mild training. The selected protocol (14-week training with sacrifice $48 \mathrm{~h}$ after the last training session) is compatible with the delayed phase of protection or SWOP (Lennon et al. 2004; Stein et al. 2004). As the underlying mechanisms should reflect alterations in gene expression profiles, the goal of the following discussion is aimed at understanding the gene mechanisms potentially involved in training-induced cardioprotection.

Because the selected training procedure did not cause cardiac hypertrophy, it is likely that it should be considered "mild". Nevertheless, the hemoglobin concentration was reduced in trained rats as observed in endurance athletes due to slight red cell hemolysis (Schumacher et al. 2002). The higher plasma MDA in trained rats marks training-induced oxidative stress. Beyond supporting this conjecture, increased $\mathrm{Mn}-$ SOD activity at constant $\mathrm{CuZn-SOD}$ indicates that mitochondria are the preferred site of formation of training-induced oxidative stress. Although increased Mn-SOD activity was reported in relation to highintensity $\left(\sim 75 \% V \mathrm{O}_{2 \max }\right)$ (Lennon et al. 2004; Moran et al. 2004), to our knowledge this is the first observation showing such an increase following mild training. Remarkably, despite higher Mn-SOD activity in the myocardium of trained vs. control animals, the relative mRNA levels did not differ in the two groups.

The observed phenotype is accompanied by upregulation of genes, proteins and activities related to the antioxidant response as assessed by array analysis (GPX-2, Por, Cox-2, HO-1), RT-PCR (Cox-2 and HO$1)$, protein level (HO-1) and enzyme activity ( $\mathrm{Mn}-$ SOD). Some of these changes have been reported in the case of ischemic preconditioning for Cox 2 and Por (Shinmura et al. 2002) as well as for HO-1 (Yet et al. 2001), and in the case of mild training for GPX2 (Chicco et al. 2006).

Mild training did not affect apoptosis, whereas the expression of Annexin $\mathrm{V}$ and $\mathrm{IkBa} / \mathrm{Mad} 3$ was upregulated in trained rats. This further supports the notion that mild training has few phenotypical effects, yet has marked effects on gene/protein expression. In support of this hypothesis, we detected increased expression of growth arrest genes in trained animals, e.g., the cyclindependent kinase inhibitor-1a/p21 ${ }^{\text {waf1, }}$ GADD153/ CHOP/DDIT3 and Mdm2.

Increase in mRNA expression of Scya21b, an inflammatory cytokine, is here reported. It is possible that a mild inflammatory response might lead to an enhancement of the defence capacities of the trained animal (Shek and Shephard 1998).

Whereas hsp70 protein was markedly increased in trained animals, Hsp70 mRNA was not upregulated. The relatively short half-life of Hsp70 mRNA (Theodorakis 
and Morimoto 1987; Yost et al. 1990) may account for the observed behaviour of this mRNA as opposed to substantial stability of Hsp70 protein. Although exercise-induced upregulation of Hsp70 has been repeatedly reported in cardiac cells (see, for example, Lennon et al. 2004; Moran et al. 2004), the underlying mechanism is not well understood (Melling et al. 2004). The well known relevance of heat shock proteins in the prevention of cardiovascular diseases (Ji 2002) may involve inhibition of apoptosis (Siu et al. 2004) and regulation of $\mathrm{Ca} 2+$ homeostasis (Liu et al. 2006), but it is likely that the protection conferred by Hsp70 may not be sufficient to explain increased ischemia tolerance (Ronchi et al. 2004) and may require additional activities, as for example those provided by HO-1 and Cox-2. The observed downregulation of other genes of the heat shock pathway, including Hsj2, Hsp60 and GRP75/PBP74, may be interpreted in terms of increased mitochondrial stress, but further studies are needed to address this issue.

It is believed that exercise-related peaks in oxygen consumption may increase the production of reactive oxygen species (ROS) and eventually the oxidative stress (Ji 2002). The latter might also stem from ischemia-reperfusion events that may occur in the correspondence of oxygen uptake peaks during the training sessions. In the specific case of mild exercise training that was examined in this study, the lack of evident signs of apoptosis, inflammation, mitochondrial and reticulum stress indicates that mild training does not necessarily cause appreciable stress nor physical strain. Furthermore, the employed model did not reveal any appreciable change in cardiac hypertrophy or whole animal homeostasis. Nevertheless, mild training could enhance myocardial defenses and resistance to $I / R$ by upregulating a number of cardioprotective and antioxidant genes and proteins. By suggesting remarkable similarities between training and ischemic preconditioning, these observations warrant further studies aimed at prescribing mild training as an efficient way to prevent cardiovascular disease in man.

Acknowledgments This study was supported by grants of the Italian Ministry of University and Research (PRIN 2004054720) and by Cariplo Foundation (2005 Project). Authors are grateful to dr. C. Ferreri for helpful discussion.

\section{References}

Bolli R (2000) The late phase of preconditioning. Circ Res 87(11):972-983

Bronikowski AM, Carter PA, Morgan TJ, Garland T Jr, Ung N, Pugh TD, Weindruch R, Prolla TA (2003) Lifelong voluntary exercise in the mouse prevents age-related alterations in gene expression in the heart. Physiol Genomics 12(2):129138

Chicco AJ, Hydock DS, Schneider CM, Haywaerd R (2006) Lowintensity exercise training during doxorubicin treatment protects against cardiotoxicity. J Appl Physiol 100(2):519-527

Chomczynski P, Sacchi N (1987) Single-step method of RNA isolation by acid guanidinium thiocyanate-phenol-chloroform extraction. Anal Biochem 162(1):156-159

Freimann S, Scheinowitz M, Yekutieli D, Feinberg MS, Eldar M, Kessler-Icekson G (2005) Prior exercise training improves the outcome of acute myocardial infarction in the rat. Heart structure, function, and gene expression. J Am Coll Cardiol 45(6):931-938

Hearse DJ (1994) Myocardial ischaemia: can we agree on a definition for the 21st century? Cardiovasc Res 28(12):17371744

Ji LL (2002) Exercise-induced modulation of antioxidant defense. Ann N Y Acad Sci 959(Apr):82-92

Kawai S, Kasashima K, Tomita M (1989) High-performance liquid chromatographic determination of malondialdehyde in serum. J Chromatogr 495:235-238

Lennon SL, Quindry JC, French JP, Kim S, Mehta JL, Powers SK (2004) Exercise and myocardial tolerance to ischaemia-reperfusion. Acta Physiol Scand 182(2):161-169

Liu J, Kam KW, Borchert GH, Kravtsov GM, Ballard HJ, Wong TM (2006) Further study on the role of HSP70 on Ca2+ homeostasis in rat ventricular myocytes subjected to simulated ischemia. Am J Physiol Cell Physiol 290(2):C583CC591

Livak JK, Schmittgen TD (2001) Analysis of relative gene expression data using real-time quantitative PCR and the $2^{-\Delta \Delta C} \mathrm{~T}$ method. Methods 25(4):402-408

Melling CW, Thorp DB, Noble EG (2004) Regulation of myocardial heat shock protein 70 gene expression following exercise. J Mol Cell Cardiol 37(4):847-855

Moran M, Delgado J, Gonzalez B, Manso R, Megias A (2004) Responses of rat myocardial antioxidant defences and heat shock protein HSP72 induced by 12 and 24-week treadmill training. Acta Physiol Scand 180(2):157-166

Powers SK, Lennon SL, Quindry J, Mehta JL (2002) Exercise and cardioprotection. Curr Opin Cardiol 17(5):495-502

Ronchi R, Marano L, Braidotti P, Bianciardi P, Calamia M, Fiorentini C, Samaja M (2004) Effects of broad band electromagnetic fields on HSP70 expression and ischemiareperfusion in rat hearts. Life Sci 75(16):1925-1936

Shek PN, Shephard RJ (1998) Physical exercise as a human model of limited inflammatory response. Can J Physiol Pharmacol 76(5):589-597

Shinmura K, Xuan YT, Tang XL, Kodani E, Han H, Zhou Y, Bolli R (2002) Inducible nitric oxide synthase modulates cyclooxygenase- 2 activity in the heart of conscious rabbits during the late phase of ischemic preconditioning. Circ Res 90(5):602-608

Schumacher YO, Schmid A, Grathwohl D, Bultermann D, Berg A (2002) Hematological indices and iron status in athletes of various sports and performances. Med Sci Sports Exerc 34(5):869-875

Schweizer NB, Alessio HM, Hagerman AE, Sashwati R, Sen CK, Nagy S, Byrnes RN, Philip BN, Woodward JL, Wiley R (2005) Access to exercise and its relation to cardiovascular health and gene expression in laboratory animals. Life Sci 77(18):2246-2261

Siu PM, Bryner RW, Martyn JK, Alway SE (2004) Apoptotic adaptations from exercise training in skeletal and cardiac muscles. FASEB J 18(10):1150-1152 
Starnes JW, Taylor RP, Ciccolo JT (2005) Habitual low-intensity exercise does not protect against myocardial dysfunction after ischemia in rats. Eur $\mathbf{J}$ Cardiovasc Prev Rehabil 12(2):169-174

Stein AB, Tang X-L, Guo Y, Xuan YT, Dawn B, Bolli R (2004) Delayed adaptation of the heart to stress: Late preconditioning. Stroke 35(11 Suppl 1):2676-2679

Strøm CC, Aplin M, Ploug T, Christoffersen TEH, Langfort J, Viese M, Galbo H, Hauns $\varnothing$ S, Søren PS (2005) Expression profiling reveals differences in metabolic gene expression between exercise-induced cardiac effects and maladaptive cardiac hypertrophy. FEBS J 272(11):2684-2695

Theodorakis N, Morimoto RI (1987) Posttranscriptional regulation of $h s p 70$ expression in human cells: effects of heat shock, inhibition of protein synthesis, and Adenovirus infection on translation and mRNA stability. Mol Cell Biol 7(12):4357-4368

Vitadello M, Penzo D, Petronilli V, Michieli G, Gomirato S, Menabò R, Di Lisa F, Gorza L (2003) Overexpression of the stress-protein Grp94 reduces cardiomyocyte necrosis due to calcium overload and simulated ischemia. FASEB J 17(8):923-925
Wisloff U, Helgerud J, Kemi OJ, Ellingsen O (2001) Intensitycontrolled treadmill running in rats: $\mathrm{VO}(2 \mathrm{max})$ and cardiac hypertrophy. Am J Physiol Heart Circ Physiol 280(3):H1301-H1310

Yet S-F, Tian R, Layne MD, Wang ZY, Maemura K, Solovyeva M, Ith B, Melo LG, Zhang L, Ingwall JS, Dzau VJ, Lee M-E, Perrella MA (2001) Cardiac-specific expression of heme oxygenase-1 protects against ischemia and reperfusion injury in transgenic mice. Circ Res 89:168-173

Yellon DM, Downey JM (2003) Preconditioning the myocardium: from cellular physiology to clinical cardiology. Physiol Rev 83(4):1113-1151

Yost HJ, Petersen RB, Lindquist S (1990) RNA metabolism: strategies for regulation in the heat shock response. Trends Genet 6(7):223-227

Zhou JY, Prognon P (2006) Raw material enzymatic activity determination: a specific case for validation and comparison of analytical methods - the example of superoxide dismutase (SOD). J Pharm Biomed Anal 40(5):1143-1148 